\title{
Eisenmenger syndrome - an electrocardiographic and echocardiographic assessment of the right ventricle
}

\author{
Valkovicova $\mathrm{T}^{1}$, Kaldararova $\mathrm{M}^{1}$, Reptova $\mathrm{A}^{1}$, Bohacekova $\mathrm{M}^{1}$, Bacharova $\mathrm{L}^{2}$, Hatala $\mathrm{R}^{1}$, Simkova $\mathrm{I}^{1}$ \\ Department of Cardiology and Angiology, Slovak Medical University and National Institute of Cardiovascular \\ Diseases, Bratislava, Slovakia. valkovicova.tatiana@gmail.com
}

\begin{abstract}
BACKGROUND: Eisenmenger syndrome represents severe, irreversible, and end-stage pulmonary arterial hypertension (PAH) associated with congenital heart defects. For long-term outcome optimal right ventricular (RV) adaptation is crucial with precise assessment of its hypertrophy, dilatation and function.

Objectives: Associations of electrocardiographic (ECG) and echocardiographic (ECHO) RV characteristics were analyzed.

METHODS: Included were 52 patients (39F/13M), median age 45 years (24-78). Following ECG parameters were analyzed: Butler-Leggett formula (B-L), Sokolow-Lyon criterion (S-L), QRS duration (QRS), maximum spatial QRS vector magnitude (QRS max); and ECHO parameters: RV diameter (RVd), RV wall thickness (RVAW), RV/LV function.

RESULTS: Following significant ECG-ECHO associations were demonstrated: S-L criterion and B-L formula with RVAW ( $<$ 0.0001); QRS with RVd $(p=0.0012)$ and QRS max inversely with RVd $(p=0.04)$; QRS > 120 ms only with severely dilated $\mathrm{RV}(\mathrm{RVd}>45 \mathrm{~mm})$, while $\mathrm{QRS} \max <14 \mathrm{~mm}$ already with mild RV dilatation $(\mathrm{RVd}>$ $33 \mathrm{~mm}$ ); A new combined scoring system was introduced.

CONCLUSIONS: In Eisenmenger syndrome RV hypertrophy is compensatory; diagnosis of prognostically unfavorable RV dilatation is therefore important. Combined ECG-ECHO analysis enables more accurate risk stratification. QRS duration > 120 ms seems to be a late marker; QRS max together with ECHO parameters may help to distinguish patients at higher risk for clinical deterioration (Tab. 3, Fig. 8, Ref. 53). Text in PDF www.elis.sk. KEY WORDS: congenital heart defects, pulmonary arterial hypertension, right ventricular hypertrophy, right ventricular dilatation, electrocardiography, echocardiography.
\end{abstract}

\section{Introduction}

Eisenmenger syndrome represents severe and end-stage pulmonary arterial hypertension $(\mathrm{PAH})$ associated with congenital heart defects (CHD) $(1,2,3)$.

The inborn presence of a communication between systemic and pulmonary circulations leads to long-term volume and pressure overload, pulmonary vascular remodeling and PAH development (4). When changes progress to an irreversible point, with shunt reversal, Eisenmenger syndrome is described $(5,6,7,8)$. This pathophysiologic evolution results finally in clinical symptoms due to systemic desaturation, cyanosis and secondary multisystemic disorders $(9,10,11,12)$.

Despite several clinical complaints, crucial factor for patient's prognosis and long-term survival is the right ventricle (RV) (12, 13). Though RV exposure to pressure overload is usually not well

${ }^{1}$ Department of Cardiology and Angiology, Slovak Medical University and National Institute of Cardiovascular Diseases, Bratislava, Slovakia, and ${ }^{2}$ International Laser Center, Bratislava, Slovakia

Address for correspondence: T. Valkovicova, MD, Department of Cardiology and Angiology, Slovak Medical University and National Institute of Cardiovascular Diseases, Pod Krasnou horkou 1, SK-833 48 Bratislava, Slovakia.

Phone: +421.259320271 , Fax: +421.259320272 tolerated $(14,15,16)$, in CHD pulmonary vascular resistance increases gradually with enough time and compensation possibilities for RV adaptation. The sufficient RV hypertrophy together with the presence of a "pop-off" valve through the defect enables to maintain good RV function for a long period of time $(17,18,19$, $20,21)$. So, despite an adverse hemodynamic situation, patients with Eisenmenger syndrome often show better outcome compared to other PAH subtypes $(22,23,24,25,26)$.

On the other hand, severe and progressive RV dilatation can lead to RV dysfunction and failure $(27,28)$. Once clinical deterioration has started, it is usually leading to death in a relatively short time. To distinguish patients with worse RV hemodynamics and to identify the turning point where RV adaptation mechanisms are exhausted may play an extremely important role $(29,30)$.

On the contrary to very well recognized diagnostic tools of defining left ventricular failure, morphological and functional evaluation of the RV is often not easy. Echocardiographic (ECHO) assessment of proper size, hypertrophy and particularly defining RV systolic function might be quite complex $(31,32,33)$. This is especially the case when attempting to predict possible short-term adverse progression to dysfunction and failure. Due to irregular and triangular shape of the RV it is not possible to achieve a complete image from a single view and often more projections and parameters are necessary to be applied. It is therefore very diffi- 

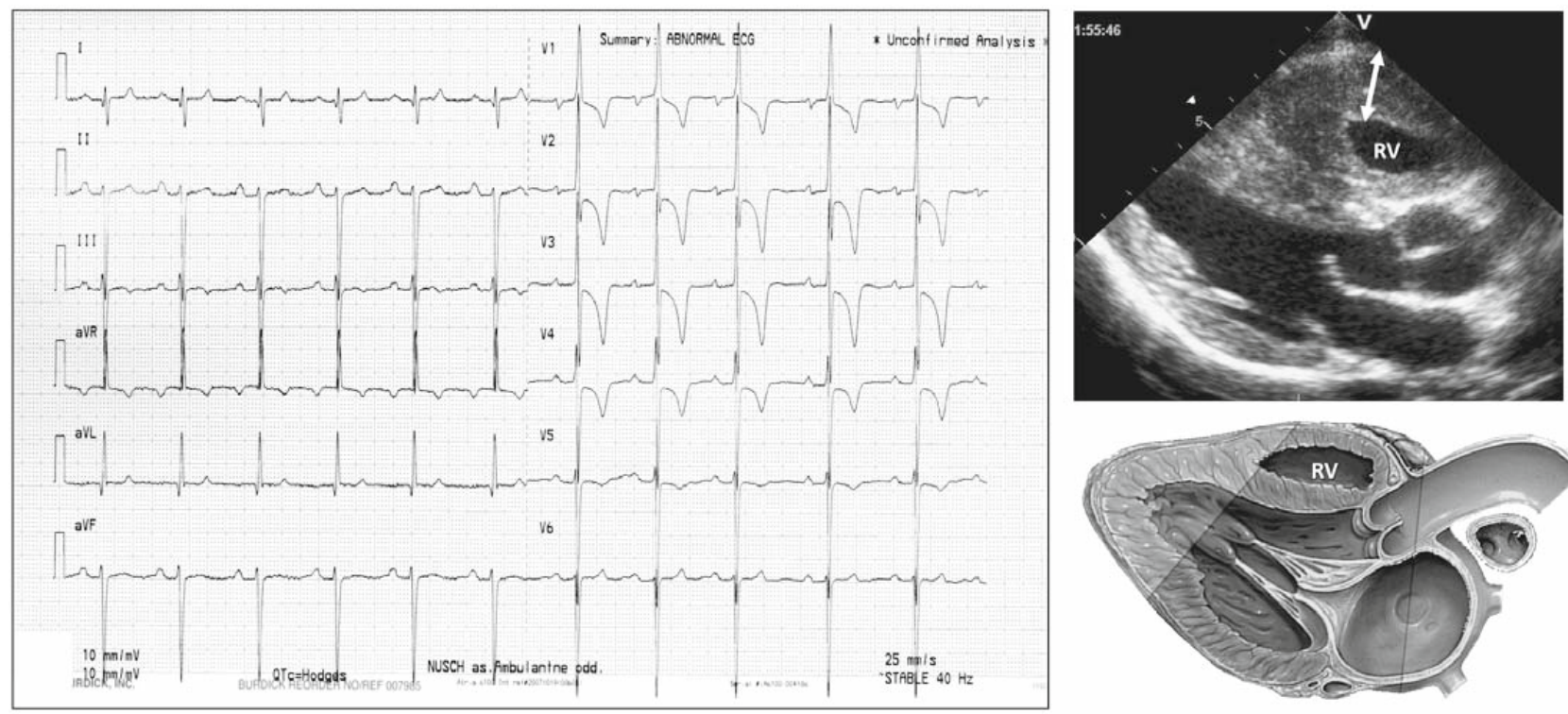

Fig. 1. ECG (A) and ECHO (B) picture of RV hypertrophy (ECG - electrocardiography, ECHO - echocardiography, RV - right ventricle).

cult to demonstrate clear correlation between ECHO determined RV size and its function.

Electrocardiographic (ECG) evaluation of the RV is nowadays mostly neglected in clinical practice and it has a rather marginal importance. Even though ECG represents a basic, first-line and most easily accessible diagnostic tool, only few parameters describe RV hypertrophy and dysfunction $(34,35,36,37,38,39,40)$.

\section{Aim of the present study was:}

- To compare RV ECG and ECHO characteristics (Fig. 1) in patients with Eisenmenger syndrome;

- To categorize parameters and cut-off points that might help to quantify the RV;

- To identify possible prognostic risk scores for RV dysfunction or patient's mortality.

\section{Materials and methods}

Fifty-two patients (39 female / 13 male) with Eisenmenger syndrome were retrospectively analyzed. Median age was 45 years (24-78 years); younger than 40 years were 21 (40.4\%) and older than 60 years were 15 patients $(28.9 \%)$. Nineteen patients $(36.5 \%)$ died during a 10 -year follow-up.

Twenty eight patients $(53.9 \%)$ had post-tricuspid congenital heart defects (ventricular septal defects, atrio-ventricular septal defect, persistent arterial duct, truncus arteriosus, pulmonary atresia) and 24 patients (46.1\%) had pre-tricuspid defects (atrial septal defects and/or partial anomalous pulmonary venous return). In 8 patients (15.4\%) an associated Down syndrome was present.

This was a cross-sectional study, analyzing all consecutive patients with Eisenmenger syndrome followed at our institution. Measured parameters were as follows:
1. ECG parameters from a 12-lead ECG:

- Butler-Leggett formula (B-L, mm; calculated as (R or R' in V1 or in $\mathrm{V} 2)+(\mathrm{S}$ in I or V6) - (S in V1));

- Sokolow-Lyon criterion for RV hypertrophy (S-L, mm; calculated as ( $\mathrm{R}$ in $\mathrm{V} 1)+(\mathrm{S}$ in V5 or in V6));

- QRS duration (QRS, ms) and maximum spatial QRS vector magnitude (QRS max, mm; calculated as the square root of $\left((\mathrm{R} \text { or } \mathrm{S} \text { in } \mathrm{V} 2)^{2}+(\mathrm{R} \text { in } \mathrm{V} 5)^{2}+(\mathrm{R} \text { in } \mathrm{AVF})^{2}\right)$.

All ECG measurements were taken as mean value from 10 manually measured QRS complexes. As normal values were considered: $\mathrm{BL}<7 \mathrm{~mm}, \mathrm{~S}-\mathrm{L}<11 \mathrm{~mm}, \mathrm{QRS}<120 \mathrm{~ms}$ and QRS max $>14 \mathrm{~mm}$.

\section{ECHO parameters:}

- RV diameter (RVd, mm);

- RV anterior wall thickness (RVAW, mm);

- RV systolic function by the tricuspid annular plane systolic excursion (TAPSE, $\mathrm{mm}$ ) and RV ventricular fractional area change (FAC, mm);

- Established were also left ventricular diameter (LVd, mm) and left ventricular ejection fraction ( $\mathrm{LV} \mathrm{EF}, \%$ ).

All parameters were taken as mean value from 3 measurements. As normal values were considered: $\mathrm{RVd} \leq 33 \mathrm{~mm}$, RVAW $<5 \mathrm{~mm}$, TAPSE $\geq 17 \mathrm{~mm}, \mathrm{FAC} \geq 36 \%$; as severe RV dilatation $\mathrm{RVd}>45 \mathrm{~mm}$, and severe RV hypertrophy RVAW $>10 \mathrm{~mm}$.

According to the presence of highly abnormal ECG and ECHO parameters $(\mathrm{B}-\mathrm{L}>18 \mathrm{~mm}, \mathrm{~S}-\mathrm{L}>18 \mathrm{~mm}$, QRS > $120 \mathrm{~ms}$, QRS $\max <14 \mathrm{~mm}, \mathrm{RVd}>33 />45 \mathrm{~mm}$, RVAW $>10 \mathrm{~mm}$ ), and combined with other risk factors (age $>40$ years, underlying defect type and Down syndrome) a new scoring system of risk factors was developed.

For statistical analysis computer programs Microsoft Excel and software package JMP 5.1 (SAS Institute, Inc., Cary, NC) were used. Continuous data are presented as median and range; nominal 
Tab. 1. Patients basic results.

\begin{tabular}{|c|c|c|c|c|}
\hline ECHO parameters $(n=52)$ & Median & (Min.-Max.) & No. of patients & $\%$ \\
\hline $\mathrm{RVd}(\mathrm{mm})$ & 32.5 & $(15-64)$ & - & - \\
\hline $\mathrm{RV}$ dilatation $(\mathrm{RVd}>33 \mathrm{~mm})$ & - & - & 24 & 46.2 \\
\hline $\mathrm{RV}$ severe dilatation $(\mathrm{RVd}>45 \mathrm{~mm})$ & - & - & 9 & 17.3 \\
\hline RVAW (mm) & 9 & $(5-19)$ & - & - \\
\hline RV severe hypertrophy (RVAW>10 mm) & - & - & 21 & 40.4 \\
\hline RV function - TAPSE $(\mathrm{mm})$ & 22 & $(11-31)$ & - & - \\
\hline RV function - TAPSE $<17 \mathrm{~mm}$ & - & - & 8 & 15.4 \\
\hline RV function - FAC (\%) & 50 & $(24-73)$ & - & - \\
\hline RV function $-\mathrm{FAC}<36 \%$ & - & - & 6 & 11.5 \\
\hline RV dysfunction (TAPSE $<17 \mathrm{~mm}$ or FAC $<36 \%$ ) & - & - & 11 & 21.2 \\
\hline LVd (mm) & 48 & $(38-56)$ & - & - \\
\hline $\mathrm{LVd}(\mathrm{mm})-$ male $/$ female & $51 / 46$ & $(46-56 / 38-52)$ & - & - \\
\hline LV EF $(\%)$ & 61 & $(55-65)$ & - & - \\
\hline$\underline{\text { LV systolic dysfunction }(\mathrm{EF}<50 \%)}$ & - & - & 0 & 0 \\
\hline ECG parameters $(n=52)$ & Median & (Min.-Max.) & No. of patients & $\%$ \\
\hline RBBB & & - & 49 & 94.2 \\
\hline Sokolow-Lyon criterion (mm) & 14.3 & $(1-46)$ & - & - \\
\hline $\mathrm{S}-\mathrm{L} \geq 7 \mathrm{~mm}$ & - & - & 40 & 76.9 \\
\hline Butler-Leggett formula (mm) & 13.5 & $(-4.5-43)$ & - & - \\
\hline $\mathrm{B}-\mathrm{L} \geq 11 \mathrm{~mm}$ & - & - & 35 & 67.3 \\
\hline QRS length (ms) & 105.5 & $(82-150)$ & - & - \\
\hline $\mathrm{QRS}<100 \mathrm{~ms}$ & - & - & 21 & 40.1 \\
\hline $\mathrm{QRS}>120 \mathrm{~ms}$ & - & - & 10 & 19.2 \\
\hline QRS max (mm) & 16.2 & $(7.4-36.5)$ & - & - \\
\hline QRS $\max <14 \mathrm{~mm}$ & - & - & 19 & 36.5 \\
\hline
\end{tabular}

B-L - Butler-Leggett formula, ECG - electrocardiography, ECHO - echocardiography, EF - ejection fraction, FAC - fractional area change, LV - left ventricle, LVd - left ventricular end-diastolic diameter, Min.-Max. - minimal and maximal value, No. pts - number of patients, QRS max - maximum spatial QRS vector magnitude, RBBB right bundle branch block, RV - right ventricle, RVAW - right ventricular wall thickness, RVd - right ventricular end-diastolic diameter, RVH - right ventricular hypertrophy, S-L - Sokolow-Lyon criterion, TAPSE - tricuspid annular plane systolic excursion

data as percentage. Univariate analysis was performed to analyze correlation between parameters. In case of continuous data nonparametric Wilcoxon test and in case of nominal data contingence tables were used. A p value $<0.05$ was considered significant.

The study was performed with patient's informed consent and in accordance with protocols approved by the institution's ethics committee.

\section{Results}

Basic functional, ECG and ECHO characteristics are listed in Table 1. In our cohort, all patients had a normal left ventricle size with no significant left ventricular dysfunction.

Tab. 2. Associations of ECG and ECHO RV hypertrophy.

\begin{tabular}{lccc}
\hline \multirow{2}{*}{ Parameters } & \multicolumn{2}{c}{$\begin{array}{c}\text { ECHO: RV hypertrophy } \\
\text { Median (Min. - Max.) }\end{array}$} \\
\cline { 2 - 4 } & $\begin{array}{c}\text { RVAW } \\
5-10 \mathrm{~mm}\end{array}$ & $\begin{array}{c}\text { RVAW } \\
>10 \mathrm{~mm}\end{array}$ & $\mathrm{p}$ \\
\hline Butler-Leggett formula (mm) & $\begin{array}{c}12 \\
(-2-32)\end{array}$ & $\begin{array}{c}19.5 \\
(-4,5-43)\end{array}$ & 0.03 \\
\hline Sokolow-Lyon criterion (mm) & $\begin{array}{c}14.4 \\
(7.4-35)\end{array}$ & $\begin{array}{c}17.5 \\
(9.4-36.5)\end{array}$ & 0.005 \\
\hline QRS length (ms) & $\begin{array}{c}104 \\
(82-150)\end{array}$ & $\begin{array}{c}108 \\
(86-150)\end{array}$ & n.s. \\
\hline QRS max (mm) & $\begin{array}{c}12 \\
12.5\end{array}$ & n.s. \\
\hline
\end{tabular}

$\overline{\text { ECG - electrocardiography, ECHO - echocardiography, Min.-Max. - minimal and }}$ maximal value, RV - right ventricle, RVAW - right ventricular wall thickness, QRS max - maximum spatial QRS vector magnitude
Following associations of ECG and ECHO parameters of RV dilatation and hypertrophy were demonstrated:

- ECG parameters of RV hypertrophy (both S-L and B-L) correlated significantly with ECHO RVAW ( $p<0.0001$ in both parameters) (Fig. 2A,B); and also with the severity of RV hypertrophy (in RVAW $>10 \mathrm{~mm}$ compared to RVAW $\leq 10 \mathrm{~mm})(\mathrm{p}=0.005$, $\mathrm{p}=0.03$ respectively) (Tab. 2 );

- No significant difference of ECHO RVAW was found in patients with normal compared to pathological values of ECG B-L or $\mathrm{S}-\mathrm{L}$ : in B-L median RVAW was 8 versus $9 \mathrm{~mm}$; and in S-L median RVAW was 8 versus $9.5 \mathrm{~mm}$;

- Though when comparing patients with S-L or B-L $>18 \mathrm{~mm}$ a significant difference of ECHO RVAW was present $(\mathrm{p}<0.0001$ in both parameters) (Fig. 3A); as well as a significant difference regarding patients with ECHO RVAW $>10 \mathrm{~mm}(\mathrm{p}=0.005$ in both parameters) (Fig. 3B);

- There was no correlation of S-L and B-L ECG parameters with ECHO RVd (Tab. 3);

- Significantly correlated ECG QRS duration and inversely correlated QRS max with ECHO RVd ( $p=0.0012, p=0.004$ respectively) (Fig. 4A,B, Tab. 3); while none of these ECG parameters correlated with ECHO RVAW (Tab. 2);

- ECG QRS duration was significantly longer in patients with ECHO RVd $>45$ mm ( $=0.0025)$ (Fig. 5A); and QRS $>120$ $\mathrm{ms}$ was significantly more frequent in patients with ECHO RVd $>45 \mathrm{~mm}(\mathrm{p}=0.00024)$ (Fig. 5B);

- ECG QRS max was significantly smaller in patients with both mild and severe ECHO RV dilatation $(\mathrm{RVd}>33 \mathrm{~mm}, \mathrm{p}=0.0071$; 
$321-329$

and $\mathrm{RVd}>45 \mathrm{~mm}, \mathrm{p}=0.01$ respectively) (Fig. $6 \mathrm{~A}$ ), and as well QRS $<14 \mathrm{~mm}$ was significantly more frequently found in patients with ECHO RVd $>33 \mathrm{~mm}(\mathrm{p}=0.0003)$ (Fig. 6B);

- A pathological finding of both ECG parameters (QRS > 120 $\mathrm{ms}$ and QRS $\max <14 \mathrm{~mm}$ ) was significantly associated with
ECHO RVd $(p=0.0005)$ (Fig. 7A), as well as with the presence of a dilated RV $(\mathrm{p}<0.0001)$ (Fig. 7B);

- Neither ECG QRS duration nor QRS max did correlate with ECHO RVAW (Tab. 2);

- No association of a single ECG parameter with ECHO RV function (TAPSE, FAC) or signs of RV dysfunction was found;

Tab. 3. Associations of ECG and ECHO RV dilatation.

\begin{tabular}{|c|c|c|c|c|c|c|}
\hline \multirow{2}{*}{ Parameters } & \multicolumn{6}{|c|}{$\begin{array}{l}\text { ECHO: RV dilatation } \\
\text { Median (Min. - Max.) }\end{array}$} \\
\hline & NOT dilated RV & $\begin{aligned} & \mathrm{RVd} \\
> & 33 \mathrm{~mm}\end{aligned}$ & $\mathrm{p}$ & NOT dilated RV & $\begin{aligned} & \mathrm{RVd} \\
> & 45 \mathrm{~mm}\end{aligned}$ & $\mathrm{p}$ \\
\hline Butler-Leggett formula (mm) & $\begin{array}{c}13.7 \\
(0-43)\end{array}$ & $\begin{array}{c}13.2 \\
(-4.5-40) \\
\end{array}$ & n.s. & $\begin{array}{c}13.7 \\
(0-43)\end{array}$ & $\begin{array}{c}12.7 \\
(9-40)\end{array}$ & n.s. \\
\hline Sokolow-Lyon criterion (mm) & $\begin{array}{c}15.7 \\
(1-41.5)\end{array}$ & $\begin{array}{c}14 \\
(3-46)\end{array}$ & n.s. & $\begin{array}{c}15.7 \\
(1-41.5)\end{array}$ & $\begin{array}{c}13.5 \\
(12-46)\end{array}$ & n.s. \\
\hline QRS length (ms) & $\begin{array}{c}98 \\
(82-150)\end{array}$ & $\begin{array}{c}109 \\
(91-150)\end{array}$ & n.s. & $\begin{array}{c}98 \\
(82-150)\end{array}$ & $\begin{array}{c}121 \\
(98-150)\end{array}$ & 0.0025 \\
\hline QRS max (mm) & $\begin{array}{c}18.3 \\
(9.5-36.5)\end{array}$ & $\begin{array}{c}12.0 \\
(7.4-29.6)\end{array}$ & 0.0071 & $\begin{array}{c}18.3 \\
(9.5-36.5)\end{array}$ & $\begin{array}{c}12.9 \\
(7.4-26)\end{array}$ & 0.001 \\
\hline
\end{tabular}

ECG - electrocardiography, ECHO - echocardiography, Min.-Max. - minimal and maximal value, RV - right ventricle, RVd - right ventricular diameter, QRS max - maximum spatial QRS vector magnitude, n.s. - not significant

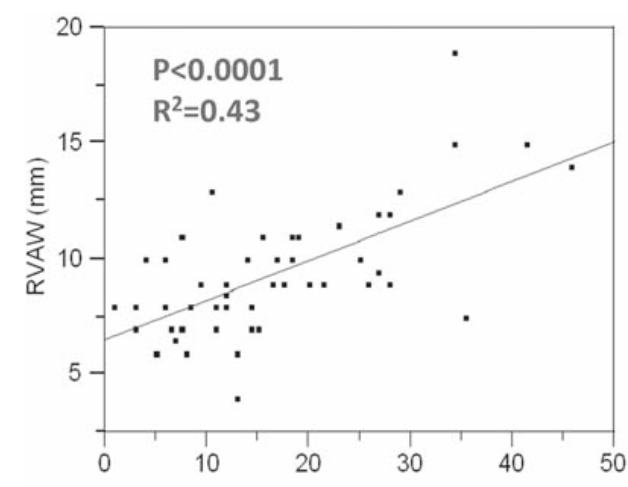

A

Sokolow-Lyon criterion

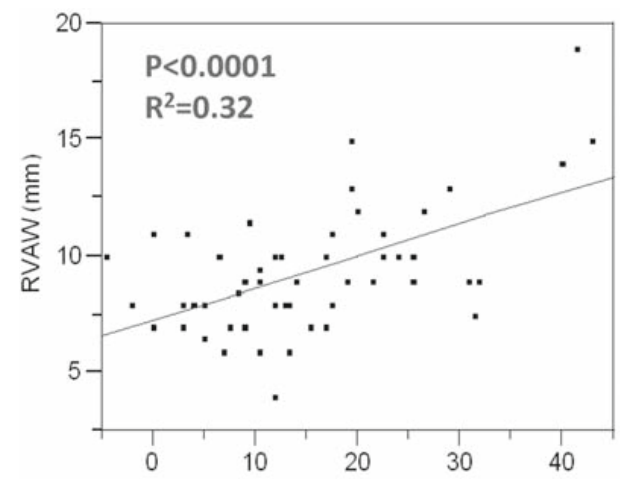

B

Butler-Leggett formula

Fig. 2. ECG and ECHO RV hypertrophy: correlation of Sokolow-Lyon criterion (A) and Butler-Leggett formula (B) with RVAW (ECG - electrocardiography, ECHO - echocardiography, RV - right ventricle, RVAW - right ventricular anterior wall thickness, RVH - right ventricular hypertrophy).
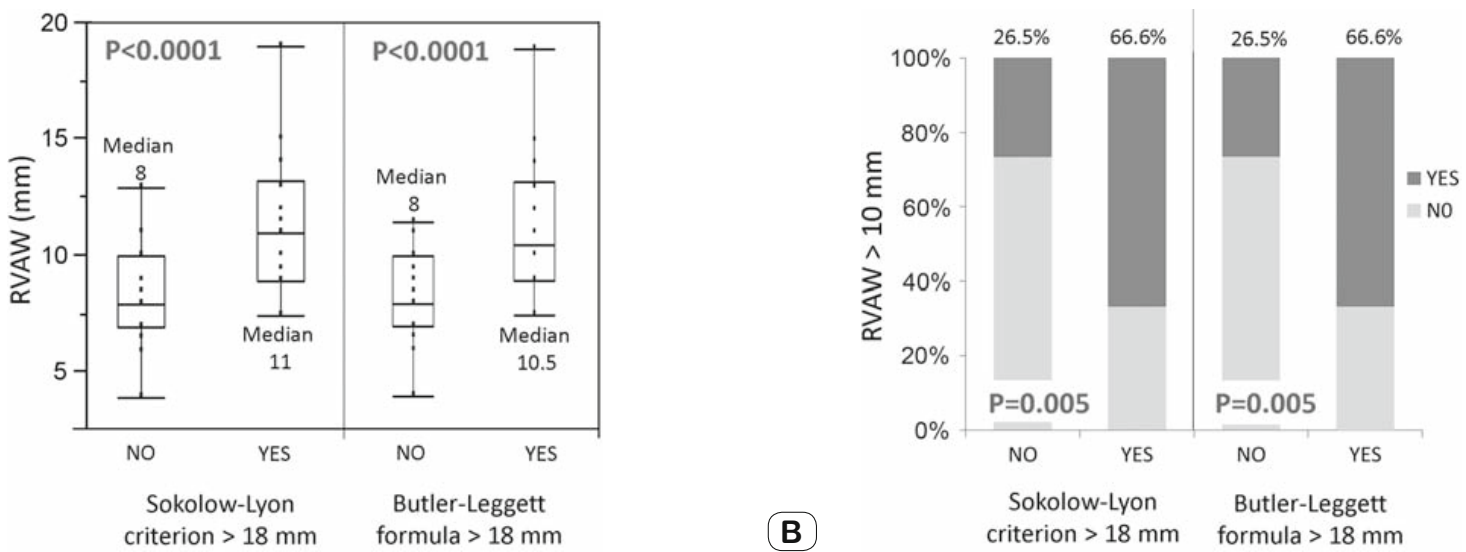

Fig. 3. ECG and ECHO RV hypertrophy: comparison of RVAW (A) according to Sokolow-Lyon criterion $>18$ mm or Butler-Leggett formula $>18 \mathrm{~mm}$ and occurrence of RVAW $>10 \mathrm{~mm}$ (B) according to Sokolow-Lyon criterion $>18 \mathrm{~mm}$ or Butler-Leggett formula $>18 \mathrm{~mm}$ (ECG electrocardiography, ECHO - echocardiography, RVAW - right ventricular anterior wall thickness). 


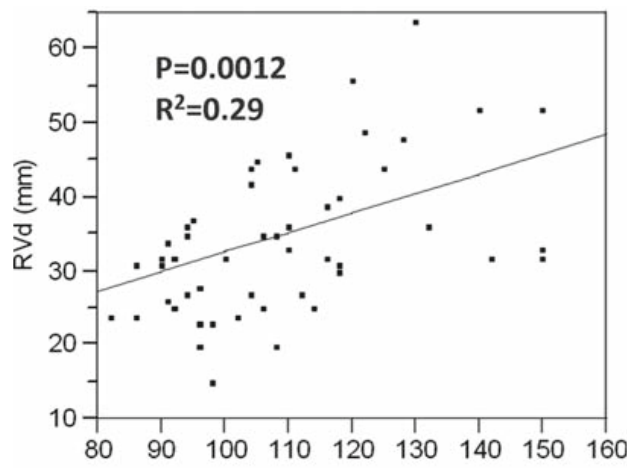

A

QRS (ms)

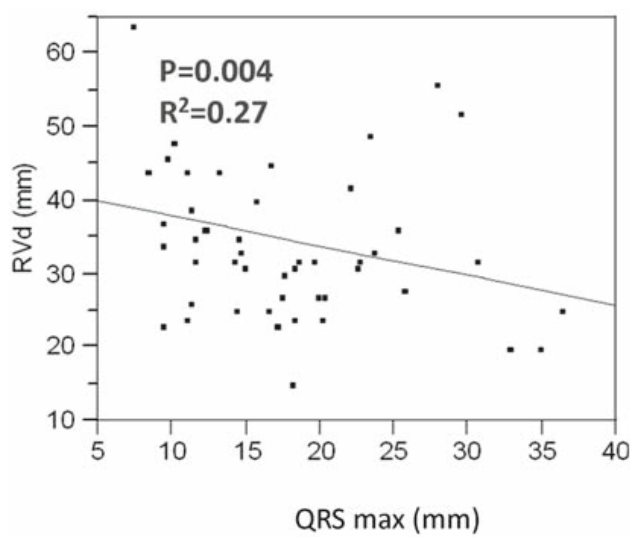

Fig. 4. ECG and ECHO RV dilatation: correlation of QRS duration (A) and inverse correlation of QRS max (B) with RVd (ECG - electrocardiography, ECHO - echocardiography, RV - right ventricle, RVd - right ventricular diameter, QRS max - maximum spatial QRS vector magnitude).

(A)

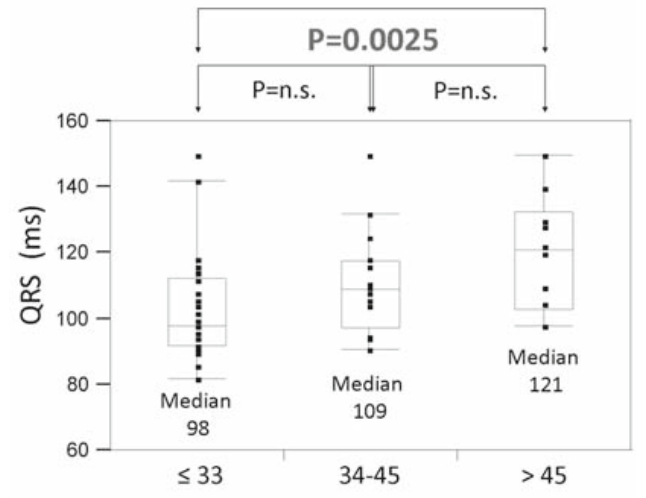

RV diameter $(\mathrm{mm})$

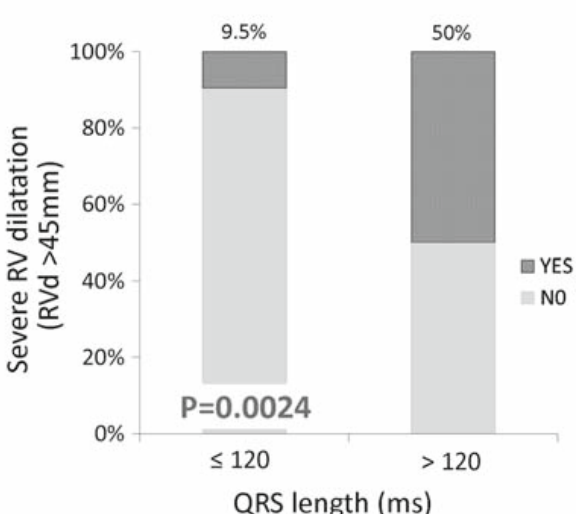

B

Fig. 5. Comparison of ECG QRS duration according to ECHO RV diameter (A) and occurrence of ECHO severe RV dilatation (RV diameter $>45 \mathrm{~mm}$ ) according to ECG QRS > $120 \mathrm{~ms}$ with (B) (ECG - electrocardiography, ECHO - echocardiography, n.s. - not significant, RV - right ventricle, $\mathrm{RVd}$ - right ventricular diameter).

(A)

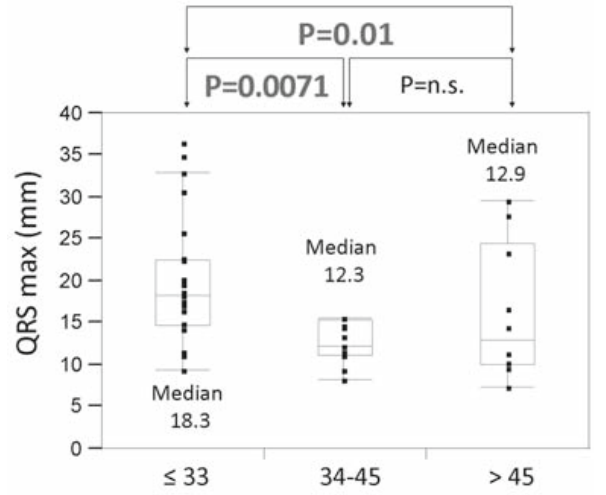

RV diameter ( $\mathrm{mm})$

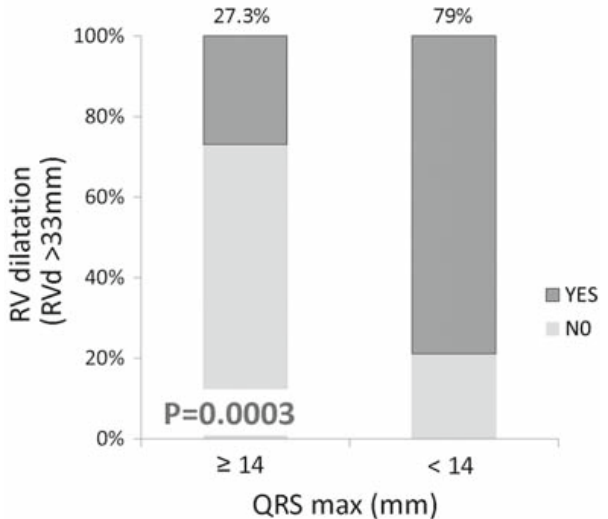

Fig. 6. Comparison of ECG QRS max according to ECHO RV diameter (A) and occurrence of ECHO RV dilatation (RV diameter > $33 \mathrm{~mm}$ ) according to ECG QRS max < 14 mm with (B) (ECG - electrocardiography, ECHO - echocardiography, n.s. - not significant, RV - right ventricle, RVd - right ventricular diameter, QRS max - maximum spatial QRS vector magnitude).

- Using our new scoring system there was a significant difference in the presence (number) of risk factors in patients with/without RV dysfunction $(\mathrm{p}=0.05)$, as well as in patients alive/death $(\mathrm{p}$ $=0.0047)$ (Fig. 8).

\section{Discussion}

Eisenmenger syndrome patients substantially differ from other patients with pulmonary arterial hypertension. Their better RV ad- 

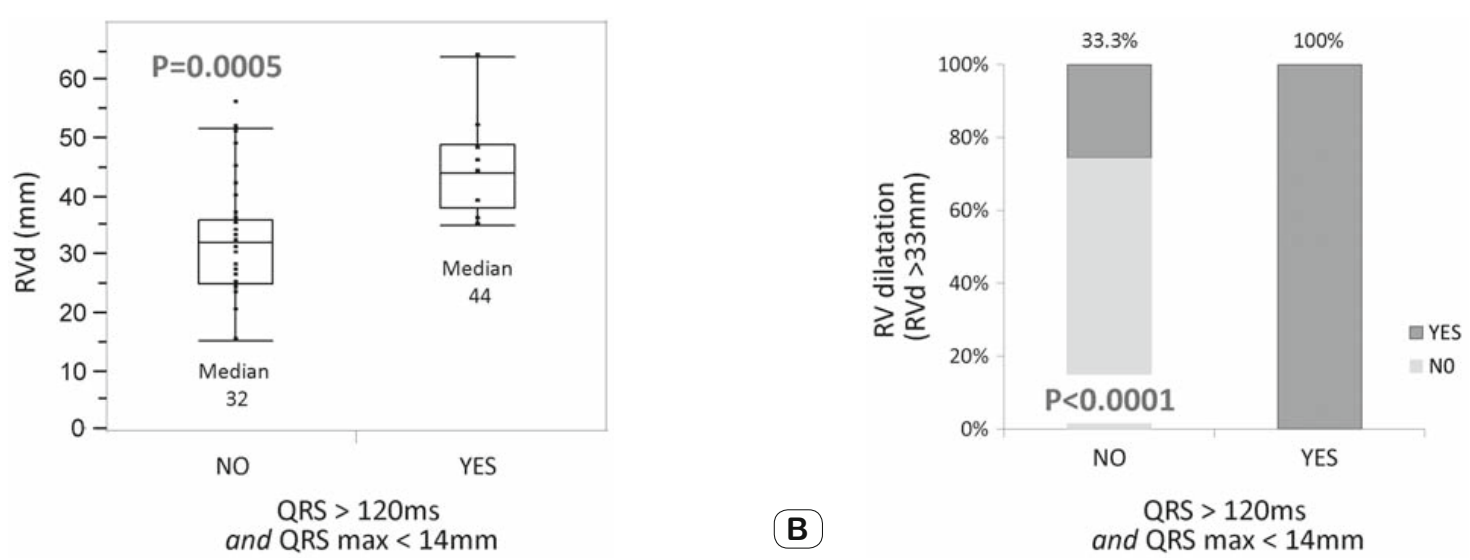

Fig. 7. Comparison of ECHO RV diameter according to ECG QRS > $120 \mathrm{~ms}$ and QRS max $<14 \mathrm{~mm}$ with (A) and occurrence of ECHO RV dilatation (RV diameter $>33 \mathrm{~mm}$ ) according to ECG QRS > $120 \mathrm{~ms}$ and QRS max $<14 \mathrm{~mm}$ (B) (ECG - electrocardiography, ECHO - echocardiography, n.s. - not significant, RV - right ventricle, RVd - right ventricular diameter, QRS - QRS length, QRS max - maximum spatial QRS vector magnitude).

\begin{tabular}{|c|c|c|}
\hline & RISK FACTORS & $\begin{array}{l}\text { SCORES } \\
\text { (points) }\end{array}$ \\
\hline U্ّ & $\begin{array}{l}\text { - Butler-Leggett } \\
\text { formula > } 18 \mathrm{~mm} \\
\text { - Sokolow-Lyon } \\
\text { criterion }>18 \mathrm{~mm} \\
\text { - QRS }>120 \mathrm{~ms} \\
\text { - QRS } \max <14 \mathrm{~mm}\end{array}$ & $\begin{array}{l}1 \\
1 \\
1\end{array}$ \\
\hline $\begin{array}{l}\text { 오 } \\
\text { ⿱ㅓㅆ }\end{array}$ & $\begin{array}{l}\text { - RV dilatation } \\
- \text { RVd }>33 \mathrm{~mm} \\
- \text { RVd }>45 \mathrm{~mm} \\
\text { - RV hypertrophy } \\
\text { - RVAW }>10 \mathrm{~mm}\end{array}$ & $\begin{array}{l}1 \\
2 \\
1\end{array}$ \\
\hline 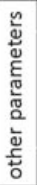 & $\begin{array}{l}\text { - Age }>40 \text { years } \\
\text { - Defect type } \\
\text { - post-tricuspid shunt } \\
\text { - pre-tricuspid shunt } \\
\text { - post closure } \\
\text { - Down syndrome }\end{array}$ & $\begin{array}{l}1 \\
0 \\
1 \\
2 \\
1\end{array}$ \\
\hline
\end{tabular}
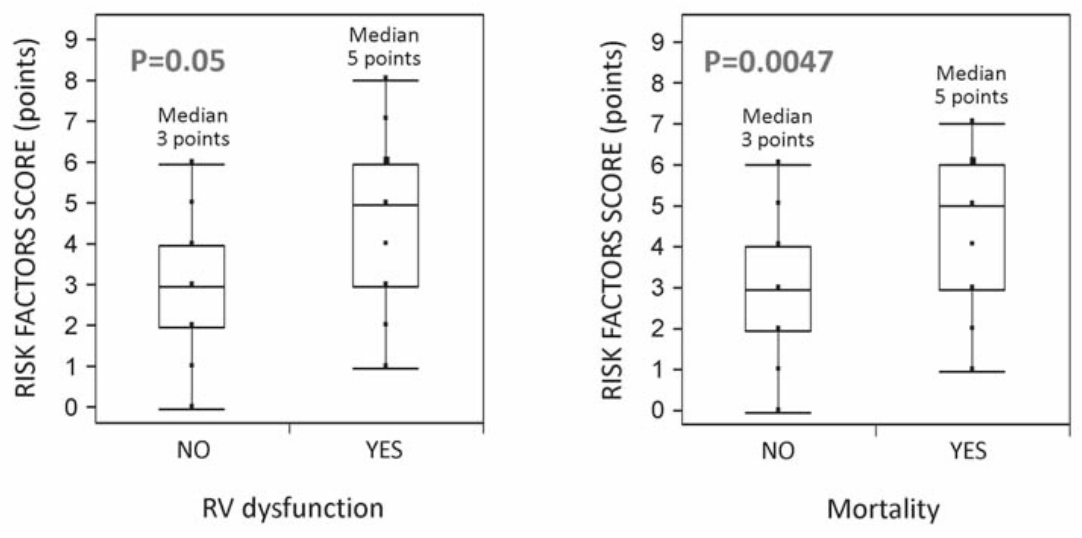

Fig. 8. Risk factors scores in patients according to RV dysfunction (A) and mortality (B) (ECG - electrocardiography, ECHO - echocardiography, RV - right ventricle, RVd - right ventricular diameter, RVAW - right ventricular wall thickness, QRS max - maximum spatial QRS vector magnitude).

aptation to pressure overload enables longer preservation of RV function, even for decades. This is traditionally considered as the crucial factor of better long-term survival $(5,12,19,21)$. On the other hand, when RV adaptation mechanisms are exhausted, rapid progressive RV dysfunction and failure often develops $(15,16,17,28)$.

Another serious problem associated with RV hypertrophy and dysfunction is the presence of arrhythmias. Arrhythmias typically occur in correlation with hemodynamic progression and RV deterioration $(33,38,41,42)$. However, new onset of arrhythmia in a previously stable patient also very frequently leads to significant clinical worsening. Although right heart hypertrophy as well as dilatation can represent a potential arrhythmogenic substrate, it is very difficult to predict at which point the patient is prone to increased risk for life-threatening arrhythmias (43, 44, 45, 46, 47, $48,49)$. It might be therefore very important to establish any relevant quantitative RV cut-off values as a prognostic marker in the long-term follow-up. This would help to improve the management of these clinically very complex patients.
The specificity of RV morphology and function continues to be an intriguing phenomenon $(21,29,50,51,52)$. Due to the importance of analyzing the RV as precisely as possible but given the difficulty to do so, there is an emerging need to use more parameters and more diagnostic modalities. Previously published studies mostly correlated isolated measurements of RV size with RV function - either by echocardiography or magnetic resonance $(13,17,19,25)$; or analyzed a single ECG parameter with RV dysfunction and/or the presence of arrhythmias $(44,45)$. We believe that our study is unique due to the combined analysis of multiple ECG and ECHO RV parameters. Such approach enables a more comprehensive characteristic of the RV.

Due to the chronic pressure overload in PAH, RV hypertrophy is the dominant hemodynamic consequence in all patients with Eisenmenger syndrome $(5,7,13,17,19,53)$. In our study there was a clear correlation between ECG and ECHO. Both ECG parameters for RV hypertrophy ( $S-L$ criterion and $B-L$ formula) correlated well with ECHO (RVAW). On the other hand, as in 
Eisenmenger syndrome all patients have more or less prominent RV hypertrophy, "normal" versus "pathological" values in neither of the analyzed ECG parameters could differentiate the degree of RV hypertrophy. Consequently, in our study we presented a new cut-off point of $18 \mathrm{~mm}$ for both parameters (B-L, as well as S-L). This level could distinguish patients with RVAW $>10 \mathrm{~mm}$, and therefore we would recommend using it as a marker for severe RV hypertrophy.

In our study, both ECG parameters seem to reflect strictly the RV wall thickness, as they did not correlate with the ECHO RV size. No other ECG parameter correlation with ECHO RV hypertrophy was found.

In patient's long-term survival $R V$ dilatation plays an important role as well. Pure volume overload is well tolerated by the $\mathrm{RV}$; however RV dilatation with pressure overload is usually a bad prognostic sign. In our study, the ECG QRS duration correlated with ECHO RV size. Though it is very difficult to establish the level of QRS prolongation that represents a relevant arrhythmogenic substrate $(3,41,43)$. In most studies with the model of pure RV volume overload (in tetralogy of Fallot after correction with severe pulmonary regurgitation) QRS $>180 \mathrm{~ms}$ is described as indication for re-intervention $(3,48)$. Yet in most other studies QRS length $>120$ ms already correlates with RV dysfunction (34, 41 ), therefore we also used this as the cut-off value. However, according to the QRS duration in our study we could not distinguish between normal size RV and dilated RV, nor between mild and severe RV dilatation. ECG QRS > 120 ms correlated only with severely dilated RV ( RVd $>45 \mathrm{~mm}$ ) and therefore in Eisenmenger syndrome we consider this a late prognostic marker.

QRS max is a very rarely analyzed marker, described in very few studies $(45,46,47)$. In our study there was an inverse correlation of ECG QRS max and ECHO RVd. In patients with decreased QRS max $<14$ mm almost $80 \%$ of them had also an ECHO dilated $\mathrm{RV}(\mathrm{RVd}>33 \mathrm{~mm})$. Above this, with both of these parameters pathological - QRS length $>120 \mathrm{~ms}$ and QRS max $<14 \mathrm{~mm}-$ all these patients were found to have an ECHO dilated RV. This could therefore represent a very useful clinical indicator.

The specificity of our study is represented by the unique combined analysis of ECHO and ECG factors; comparable study to our knowledge was not published so far. Except for this, we presented an innovative scoring system, using not only traditionally known risk factors like age $>40$ years, underlying defect type, and associated Down syndrome but joining them together with ECG and ECHO parameters, and even producing cut-off points for severe $\mathrm{RV}$ affection. This scoring system was able to depict patients with high risk and showed significant difference according to RV dysfunction as well as mortality. Our study limitation is nevertheless the lack of serial evaluation that would verify this long-term RV risk assessment concept.

\section{Learning points}

- Significant ECG and ECHO correlations of RV hypertrophy and dilatation were found in this specific patient population;

- ECG parameters of RV hypertrophy (Butler-Leggett formula and
Sokolow-Lyon criteria) correlated with ECHO RV hypertrophy (RVAW) but not with RV size;

- ECG QRS length and QRS maximal vector magnitude correlated reversely with ECHO RV dilatation but not with RV hypertrophy;

- QRS length> $120 \mathrm{~ms}$ correlated with severely dilated RV (RVd $>45 \mathrm{~mm}$ ), and QRS $\max <14 \mathrm{~mm}$ correlated already with mild $\mathrm{RV}$ dilatation ( $\mathrm{RVd}>33 \mathrm{~mm})$;

- New scoring system of ECG and ECHO parameters, together with age, defect type and Down syndrome was presented.

\section{Conclusions}

Despite the traditionally described good long-term survival of patients with Eisenmenger syndrome, repeated clinical multimodality evaluation of the right ventricle during follow-up is crucial for detecting imminent deterioration. Besides clinical and functional testing it is important to analyze echocardiographic and electrocardiographic parameters, as they are easily available at every follow-up visit of the patient. This may allow for a better prognostic stratification and identification of patients at higher risk, even before severe right ventricular dysfunction or malignant arrhythmias occur.

\section{References}

1. Eisenmenger V. Die angeborenen Defekte der Kammerscheidewand des Herzens. Z Klin Med 1897; 32: 1-28.

2. Wood P. The Eisenmenger syndrome or pulmonary hypertension with reversed central shunt. Br Med J 1958; 2 (5099): 755-762.

3. Baumgartner H, Bonhoeffer P, De Groot NMS et al. ESC Guidelines for the management of grown-up congenital heart disease (new version 2010). Eur Heart J 2010; 31: 2915-2957. doi: 10.1093/eurheartj/ehq249.

4. Galiè N, Humbert M, Vachiery J-L et al. 2015 ESC/ERS Guidelines for the diagnosis and treatment of pulmonary hypertension: The Joint Task Force for the Diagnosis and Treatment of Pulmonary Hypertension of the European Society of Cardiology (ESC) and the European Respiratory Society (ERS): Endorsed by: Association for European Paediatric and Congenital Cardiology (AEPC), International Society for Heart and Lung Transplantation (ISHLT). Eur Heart J 2016; 37 (1): 67-119. doi: org/10.1093/eurheartj/ehv317.

5. Kaemmerer H, Mebus S, Schulze-Neick I et al. The Adult Patient with Eisenmenger Syndrome: A Medical Update after Dana Point Part I: Epidemiology, Clinical Aspects and Diagnostic Options. Curr Cardiol Rev 2010; 6 (4): 343-355. doi: 10.2174/157340310793566154.

6. Simkova I, Tavacova M, Kanalikova K, Pacak J, Kaldararova M. Clinical and hemodynamic picture of Eisenmenger syndrome. Bratisl Lek Listy 2009; 110 (12): 788-794.

7. Dimopoulos K, Wort SJ, Gatzoulis MA. Pulmonary hypertension related to congenital heart disease: a call for action. Eur Heart J 2014; 35 : 691-700. doi: 10.1093/eurheartj/eht437.

8. Kaldararova M, Valkovicova T, Simkova I. Pulmonary hypertension and congenital heart diseases. Kardiol Prax 2016; 14 (4): 184-190.

9. D’Alto M, Diller GP. Pulmonary hypertension in adults with congenital heart disease and Eisenmenger syndrome: current advanced management strategies. Heart 2014; 100 (17): 1322-1328. doi: 10.1136/ heartjnl-2014-305574. 
10. Valkovicova T, Kaldararova M, Bohacekova M, Šimkova I. Eisenmenger syndrome - course, complications and management. Kardiol Prax 2014; 12 (3-4): 116-122.

11. Valkovicova T, Kaldararova M, Bohacekova M, Šimkova I. Multisystemic affection in congenital heart defects with cyanosis. Interna med 2014; 14 (3): 98-104.

12. Nashat H, Kempny A, McCabe $C$ et al. Eisenmenger syndrome: current perspectives. Research Reports in Clinical Cardiology 2017; 8: 1-12. https://doi.org/10.2147/RRCC.S117838.

13. Fine NM, Chen L, Bastiansen PM et al. Outcome prediction by quantitative right ventricular function assessment in 575 subjects evaluated for pulmonary hypertension. Circ Cardiovasc Imag 2013; 6 (5):711-721. doi: 10.1161/CIRCIMAGING.113.000640.

14. Dell'Italia LJ. Anatomy and physiology of the right ventricle. Cardiol Clin 2012; 30 (2): 167-187. doi: 10.1016/j.ccl.2012.03.009.

15. Vonk-Noordegraaf A, Haddad F, Chin KM et al. Right heart adaptation to pulmonary arterial hypertension: physiology and pathobiology. J Am Coll Cardiol 2013; 62 (25 Suppl): D22-33. doi: 10.1016/j. jacc.2013.10.027.

16. Ryan JJ, Archer SL. The Right Ventricle in Pulmonary Arterial Hypertension: Disorders of metabolism, angiogenesis and adrenergic sygnalling in right ventricular failure. Circ Res 2014; 115 (1): 176-188. doi: 10.1161/ CIRCRESAHA.113.301129.

17. Van De Bruaene A, De Meester $P$, Voigt JU et al. Right ventricular function in patients with Eisenmenger syndrome. Am J Cardiol 2012; 109 (8): 1206-1211. doi: 10.1016/j.amjcard.2011.12.003.

18. Simkova I. Eisenmenger syndrome - a unique form of pulmonary arterial hypertension. Bratisl Lek Listy 2009; 110 (12): 757-764.

19. Simkova I, Kaldararova M. Right ventricle in severe pulmonary hypertension in congenital heart defects - different and specific. Vnitr Lek 2014; 60 (4): 359-365.

20. Vonk-Noordegraaf A, Westerhof BE, Westerhof N. The Relationship Between the Right Ventricle and its Load in Pulmonary Hypertension. J Am Coll Cardiol 2017; 69 (2): 236-243. https://doi.org/10.1016/j. jacc.2016.10.047.

21. Amsallem M, Sweatt AJ, Aymami MC et al. Right Heart EndSystolic Remodeling Index Strongly Predicts Outcomes in Pulmonary Arterial Hypertension: Comparison With Validated Models. Circ Cardiovasc Imag 2017; 10 (6). pii: e005771. doi: 10.1161/CIRCIMAGING.116.005771

22. Clave MM, Maeda NY, Castro CRP et al. Factors influencing outcomes in patients with Eisenmenger syndrome: a nine-year follow-up study. Pulmonary Circulation 2017; 7 (3): 635-642. doi: $10.1177 / 2045893217721928$.

23. Diller GP, Körten MA, Bauer UM et al. Current therapy and outcome of Eisenmenger syndrome: data of the German National Register for congenital heart defects. Eur Heart J 2016; 37 (18): 1449-1455. doi: 10.1093/eurheartj/ehv743.

24. Hascoet S, Fournier E, Jaïs X et al. Outcome of adults with Eisenmenger syndrome treated with drugs specific to pulmonary arterial hypertension: A French multicentre study. Arch Cardiovasc Dis 2017; 110 (5): 303-316. doi: 10.1016/j.acvd.2017.01.006.

25. Moceri P, Kempny A, Liodakis E et al. Physiological differences between various types of Eisenmenger syndrome and relation to outcome. Int J Cardiol 2015; 179: 455-460. doi: 10.1016/j.ijcard.2014.11.100.
26. Bohacekova M, Kaldararova M, Valkovicova T, Remkova A, Vesely J, Simkova I. Risk factors detection in chronic thromboembolic pulmonary hypertension, a tool for risk quantification? Bratisl Med J 2016; 117 (10): 577-582. doi: 10.4149/BLL_2016_112.

27. Kaldararova M. Why is pulmonary hypertension so frustrating? Bratisl Lek Listy 2009; 110 (9): 536-543.

28. Van de Veerdonk MC, Marcus JT, Westerhof $\mathbf{N}$ et al. Signs of Right Ventricular Deterioration in Clinically Stable Patients with Pulmonary Arterial Hypertension. Chest 2015; 147 (4): 1063-1071. https://doi. org/10.1378/chest.14-0701.

29. Altin SE, Schulze PC. Metabolism of the right ventricle and the response to hypertrophy and failure. Progress in Cardiovascular Diseases 2012; 55 (2): 229-233. https://doi.org/10.1016/j.pcad.2012.07.010.

30. Friedberg MK, Redington AN. Right versus left ventricular failure: differences, similarities, and interactions. Circulation 2014; 129: 10331044. https://doi.org/10.1161/CIRCULATIONAHA.113.001375

31. Rudski LG, Lai WW, Afilalo J et al. Guidelines for the echocardiographic assessment of the right heart in adults: a report from the American Society of Echocardiography endorsed by the European Association of Echocardiography, a registered branch of the European Society of Cardiology, and the Canadian Society of Echocardiography. J Am Soc Echocardiogr 2010; 23: 685-713. doi: 10.1016/j.echo.2010.05.010

32. Lang RM, Badano LP, Mor-Avi V et al. Recommendations for cardiac chamber quantification by echocardiography in adults: an update from the American Society of Echocardiography and the European Association of Cardiovascular Imaging. Eur Heart J Cardiovasc Imaging 2015;16 (3): 233-70. doi: 10.1093/ehjci/jev014.

33. Karas MG, Kizer JR. Echocardiographic assessment of the right ventricle and associated hemodynamics. Progress in Cardiovascular Diseases 2012; 55 (2): 144-160. https://doi.org/10.1016/j.pcad.2012.07.011.

34. Surawicz B, Childres R, Deal BJ, Gettes LS. AHA/ACCF/HRS Recommendations for Standardization and Interpretation of Electrocardiogram. Part III: Intraventricular Conduction Disturbances. Circulation 2009; 119: e235-e240. doi: 10.1161/CIRCULATIONAHA.108.191095.

35. Buttler PM, Leggett SI, Howe CM et al. Identification of electrocardiographic criteria for diagnosis of right ventricular hypertrophy due to mitral stenosis. Am J Cardiol 1986; 57: 639-643.

36. Sokolow M, Lyon TP. The ventricular complex in right ventricular hypertrophy as obtained by unipolar and limb leads. Am Heart J 1949; 38: $273-294$.

37. Whitman IR, Patel VV, Soliman EZ et al. Validity of Surface Electrocardiogram Criteria for Right Ventricular Hypertrophy. The MESA-RV Study. J Am Coll Cardiol 2014; 63: 672-681. http://dx.doi.org/10.1016/j. jacc.2013.08.1633.

38. Nagai T, Kohsaka S, Murata M et al. Significance of electrocardiographic right ventricular hypertrophy in patients with pulmonary hypertension with or without right ventricular systolic dysfunction. Intern Med 2012; 51 (17): 2277-2283. doi: 10.2169/internalmedicine.51.7731

39. Bacharova L, Baum OV, Muromtseva GA et al. The relation between QRS amplitude and left ventricular mass in patients with hypertension identified at screening. Anadolu Kardiyol Derg 2007; 7 (Suppl 1): 153-158.

40. Goncalvesova E, Luknar M, Lesny P. ECG signs of right ventricular hypertrophy may help distinguish pulmonary arterial hypertension and pulmonary hypertension due to left ventricular diastolic dysfunction. Bratisl Lek Listy 2011; 112 (11): 614-618. 
41. Kashani A, Barold SS. Significance of QRS Complex Duration in Patients With Heart Failure. J Am Coll Cardiol 2005; 46 (12): 2183-2192. doi: 10.1016/j.jacc.2005.01.071.

42. Kaldararova M, Balazova E, Bordacova et al. Arrhythmias in congenital heart defects. Bratisl Lek Listy 2007; 108 (1): 14-19.

43. Priori SG, Blomström-Lundqvist C, Mazzanti A et al. 2015 ESC Guidelines for the management of patients with ventricular arrhythmias and the prevention of sudden cardiac death: The Task Force for the Management of Patients with Ventricular Arrhythmias and the Prevention of Sudden Cardiac Death of the European Society of Cardiology (ESC). EP Europace 2015; 17 (11): 1601-1687. https://doi.org/10.1093/europace/euv319.

44. Khairy P. Ventricular arrhythmias and sudden cardiac death in adults with congenital heart disease. Heart 2016; 102: 1703-1709. doi: 10.1136/ heartjnl-2015-309069.

45. Cortez D, Ruckdeschel E, McCanta AC et al. Vectorcardiographic predictors of ventricular arrhythmia inducibility in patients with tetralogy of Fallot. J Electrocardiol 2015; 48 (2): 141-144. doi: 10.1016/j.jelectrocard.2014.11.009.

46. Bacharova L, Tkacova R. The effect of obstructive sleep apnea on QRS complex morphology. J Electrocardiol 2015; 48 (2): 164-170. http:// doi.org/19.1016/j.jelectrocard.2014.12.007.

47. Khairy P. QRS Vector Magnitude as a Predictor of Ventricular Arrhythmias in Tetralogy of Fallot: Does it Add Up? JACC: Clinical Electrophysiology 2017; 3 (2): 171-173. doi: 10.1016/j.jacep.2016.09.015.
48. Cortez D, Barham W, Ruckdeschel E, et al. Noninvasive Predictors of Ventricular Arrhythmias in Patients With Tetralogy of Fallot Undergoing Pulmonary Valve Replacement. JACC: Clinical Electrophysiology 2017; 3 (2): 162-170. https://doi.org/10.1016/j.jacep.2016.08.007.

49. Kantorova A, Kaldararova M, Neuschl V, Nosal M, Masura J. The optimal timing for magnetic resonance imaging in long-term follow-up of patients after a complete correction of the Tetralogy of Fallot. Bratisl Lek Listy 2011; 112 (12): 679-685.

50. Foschi M, Di Mauro M, Tancredi F et al. The Dark Side of the Moon: The Right Ventricle. J Cardiovasc Dev Dis 2017; 4 (4): pii: E18. doi: $10.3390 /$ jcdd 40418 .

51. Guimaron S, Guihaire J, Amsallem M, Haddad F, Fadel E, Mercier O. Current Knowledge and Recent Advances of Right Ventricular Molecular Biology and Metabolism from Congenital heart Disease to Chronic Pulmonary Hypertension. Biomed Research International 2018: https://doi.org/10.1155/2018/1981568.

52. Asosingh K, Erzurum S. Mechanisms of right heart disease in pulmonary hypertension (2017 Grover Conference Series). Pulm Circ 2018; 8 (1): doi: $10.1177 / 2045893217753121$.

53. Simkova I, Kaldararova M. Heart failure in congenital heart defects in adulthood. 553-572. In: Goncalvesová E (Ed). Heart failure. Bratislava: ProLitera, 2016.

Received February 21, 2018 Accepted March 19. 2018. 